\title{
Efficacy of amelogenin-chitosan hydrogel in biomimetic repair of human enamel in pH-cycling systems
}

\author{
Qichao Ruan ${ }^{1}$, David Liberman ${ }^{1}$, Rucha Bapat ${ }^{1}$, Karthik Balakrishna Chandrababu ${ }^{1}$, Jin-Ho Phark ${ }^{2}$, \\ J anet Moradian-Oldak ${ }^{1}$
}

1. Center for Craniofacial Molecular Biology, Division of Biomedical Sciences, Herman Ostrow School of Dentistry, University of Southern California, Los Angeles, USA. 2. Division of Restorative Sciences, Herman Ostrow School of Dentistry, University of Southern California, Los Angeles, USA.

Correspondence: Janet Moradian-Oldak. Address: Center for Craniofacial Molecular Biology, Herman Ostrow School of Dentistry, University of Southern California, Los Angeles, CA 90033, USA. Email: joldak@usc.edu

Received: August 17, 2015

Accepted: October 19, $2015 \quad$ Online Published: November 2, 2015

DOI : $10.5430 /$ jbei.v2n1p119

URL: http://dx.doi.org/10.5430/jbei.v2n1p119

\begin{abstract}
Amelogenin-chitosan (CS-AMEL) hydrogel has shown great potential for the prevention, restoration, and treatment of defective enamel. As a step prior to clinical trials, this study aimed to examine the efficacy of CS-AMEL hydrogel in biomimetic repair of human enamel with erosive or caries-like lesions in pH-cycling systems. Two models for enamel defects, erosion and early caries, were addressed in this study. Two $\mathrm{pH}$-cycling systems were designed to simulate the daily cariogenic challenge as well as the nocturnal $\mathrm{pH}$ conditions in the oral cavity. After $\mathrm{pH}$ cycling and treatment with CS-AMEL hydrogel, a synthetic layer composed of oriented apatite crystals was formed on the eroded enamel surface. CS-AMEL repaired the artificial incipient caries by re-growing oriented crystals and reducing the depth of the lesions by up to $70 \%$ in the $\mathrm{pH}$-cycling systems. The results clearly demonstrate that the CS-AMEL hydrogel is effective at the restoration of erosive and carious lesions under $\mathrm{pH}$-cycling conditions.
\end{abstract}

\section{Key words}

Amelogenin-chitosan hydrogel, Enamel biomimetic, pH-cycling, Enamel erosion, Early carious lesion

\section{I ntroduction}

Dental enamel is the hardest tissue in human body and forms the outer layer of the tooth, providing protection against physical and chemical damage during dental function. Unlike other mineralized tissues, mature enamel is a non-living tissue and cannot regenerate after the substantial mineral loss that often occurs due to dental caries or erosion. Dental erosion is one of the most common human diseases and affects the vast majority of individuals. It can be defined as an irreversible loss of dental hard tissue due to a chemical process without the involvement of microorganisms ${ }^{[1]}$. The causative agents are usually demineralizing acidic substances, such as foods, beverages, and gastroesophageal reflux ${ }^{[2]}$. Another worldwide chronic oral disease is dental caries, which is caused by acid-producing bacteria on the teeth. Caries presents as progressive subsurface demineralization and ultimately results in mechanical failure and cavitation ${ }^{[3,4]}$. In contrast to an erosive lesion, an incipient carious lesion in enamel possesses a typical micromorphology with a 
pseudo-intact surface layer on top of the subsurface body of the lesion as a result of re-precipitating minerals ${ }^{[5]}$. Despite efforts to remineralize enamel using agents containing fluoride or casein phosphopeptide-amorphous calcium phosphate (CPP-ACP) ${ }^{[6,7]}$, the prevention and treatment of incipient carious lesions and submicrometer erosion are still major clinical challenges. Currently, advanced lesions are treated by removing the compromised tissue and filling the resulting cavity with restorative materials, such as amalgam, composites, or ceramics. These restorations fail over time due to the more or less weak adhesion at the interface between the original enamel and the artificial materials, with secondary caries often forming at this interface.

As a potential alternative to conventional treatment, biomimetic reconstruction of tooth enamel may provide an ideal solution that regrows organized enamel-mimicking apatite crystals with robust attachment to the natural enamel surface ${ }^{[8]}$. Such an approach will lead to a strong tooth surface and will eliminate the problem of secondary caries. Biomimetic strategies for enamel repair have therefore attracted increasing interest in materials science and dentistry, and are widely considered to be promising approaches to the prevention, restoration, and treatment of defective enamel. In our recent studies, we developed a biomimetic amelogenin-containing chitosan (CS-AMEL) hydrogel for superficial enamel reconstruction ${ }^{[9-11]}$. Amelogenin is the most abundant protein in forming enamel and is essential for organization of its characteristic prismatic pattern, control of crystal size and regulation of oriented and elongated crystal growth ${ }^{[12]}$. We found that amelogenin assemblies carried in chitosan hydrogel could stabilize Ca-P clusters and arrange them into linear chains, which could fuse with enamel crystals and then develop into enamel-like co-aligned crystals. The chitosan used as a carrier did not affect the crystal orientation but demonstrated the potential to protect repaired enamel from secondary caries and erosion due to its apparent antimicrobial and $\mathrm{pH}$-responsive properties. After treatment with CS-AMEL hydrogel, an organized enamel-like layer formed on the etched enamel surface, significantly improving its hardness and elastic modulus ${ }^{[9]}$. Most importantly, this biomimetic in situ regrowth of apatite crystals generated a robust enamelrestoration interface, which is important for ensuring the efficacy and durability of restorations.

It should be noted that, in order to produce formation of apatite on enamel in vitro, artificial saliva was used in our previous studies to provide an ion concentration similar to that of human saliva, with the $\mathrm{pH}$ remaining at a constant 7.0. However, natural saliva is a more complicated environment for enamel remineralization, due in part to regular variations in $\mathrm{pH}$ conditions. Normal salivary $\mathrm{pH}$ is from 6 to 7 but varies over a wider range according to fluctuations in salivary flow, from 5.3 (low flow) to 7.8 (peak flow) ${ }^{[13]}$. A clinical study has shown that the oral $\mathrm{pH}$ could change immediately to $3.8 \sim 5.4$ after consuming a variety of beverages ${ }^{[14]}$. As a result, to generate reliable data promoting an appropriate design for clinical trials, it is important to evaluate the effectiveness of the CS-AMEL hydrogel at promoting enamel regrowth under more realistic model conditions in vitro.

Among in vitro protocols, $\mathrm{pH}$-cycling models have become the preferred method to evaluate the anti-caries efficacy of developing and recently marketed products ${ }^{[15,16]}$. In the typical $\mathrm{pH}$-cycling models, dental substrates (enamel or dentin) are subjected to a scheme in which a $\mathrm{pH}$-neutral environment is periodically interrupted by acid challenges, simulating what occurs in the mouth when sugars are metabolized ${ }^{[17,18]}$. In this way, they mimic the dynamics of mineral loss and gain involved in caries formation, which is an important advantage of $\mathrm{pH}$-cycling models ${ }^{[19]}$. Other advantages include the high level of scientific control and the resulting lower variability intrinsic to in vitro models, as well as the smaller necessary sample size ${ }^{[19,20]}$. These key advantages have made $\mathrm{pH}$-cycling models a superior tool for improving understanding of the caries process and evaluating developing materials in vitro.

As a necessary step prior to clinical trails, the present study aimed to investigate the efficacy of CS-AMEL hydrogel for biomimetic repair of human enamel under $\mathrm{pH}$-cycling conditions. We addressed models of two types of enamel defects: erosion and early carious lesions. After treatment with CS-AMEL hydrogel under pH-cycling conditions, the morphology and composition of the repaired enamel were characterized by scanning electron microscopy (SEM) and X-ray diffraction (XRD), and the depths of the caries-like lesions were observed by fluorescent microscopy. 


\section{Materials and methods}

\subsection{Chemicals}

All chemicals used in this investigation were analytical grade and used as received without further purification. Chitosan (medium molecular weight, $75 \%-85 \%$ deacetylated) and calcium chloride $\left(\mathrm{CaCl}_{2}\right)$ were purchased from Sigma-Aldrich, the other chemicals were obtained from VWR.

\subsection{Enamel specimen preparation}

Human third molars (extracted following the standard procedures for extraction at the Herman Ostrow School of Dentistry of the University of Southern California and handled with approval of the Institutional Review Board) without any lesions, cracks, or fluoric mottling were selected. These teeth were cut into 3 or 4 blocks using a low-speed diamond saw (SYJ-150, MTI corporation) cooled by water. The enamel surfaces of the blocks were sequentially polished with silicon carbide paper (1,200 and 4,000 grit, Carbimet, Buehler) to create flat, uncontaminated surfaces. A window of sound enamel approximately $4 \mathrm{~mm}^{2}$ was delineated by the application of 2 coats of acid-resistant nail varnish (L'Oreal) on the block surface.

\subsection{Caries-like and erosive lesion preparation}

To prepare the erosive lesions, the enamel blocks were etched using $30 \%$ phosphoric acid $\left(\mathrm{H}_{3} \mathrm{PO}_{4}\right)$ for 30 seconds ${ }^{[10]}$. The caries-like lesions were produced by immersing the enamel blocks in a demineralization solution $\left(1.5 \mathrm{mM} \mathrm{CaCl}_{2}, 0.9 \mathrm{mM}\right.$ $\mathrm{NaH}_{2} \mathrm{PO}_{4}, 50 \mathrm{mM}$ Acetate Buffer, $\mathrm{pH} 4.6$ ) at $37^{\circ} \mathrm{C}$ for 7 days ${ }^{[16]}$.

\subsection{Preparation of amelogenin-chitosan hydrogel}

Recombinant full-length porcine amelogenin $\mathrm{rP} 172$ was expressed in E. coli and purified as described previously ${ }^{[10]}$. The amelogenin-chitosan (CS-AMEL) hydrogel was prepared by mixing chitosan (medium molecular weight, 75\%-85\% deacetylated, Sigma-Aldrich) solution $(960 \mathrm{ml}, 2 \% \mathrm{~m} / \mathrm{v}), \mathrm{Na}_{2} \mathrm{HPO}_{4}(15 \mu \mathrm{l}, 0.1 \mathrm{M}), \mathrm{CaCl}_{2}(25 \mu \mathrm{l}, 0.1 \mathrm{M})$ and amelogenin rP172 $(200 \mu \mathrm{g})$, followed by stirring at room temperature overnight. The $\mathrm{pH}$ value was adjusted to 6.5 with $1 \mathrm{M} \mathrm{NaOH}$.

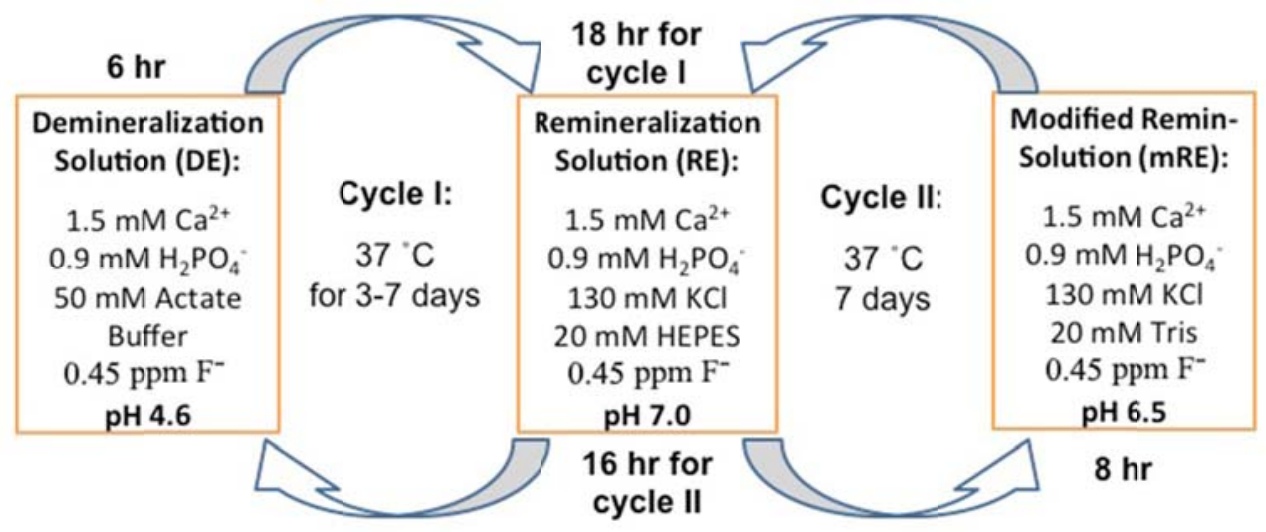

Figure 1. Schematic illustration of the $\mathrm{pH}$-cycling models

\subsection{CS-AMEL hydrogel treatments and pH cycling}

To test whether application of CS-AMEL hydrogel affected remineralization and demineralization behaviors of both caries-like and erosive lesions, the enamel blocks were subjected to a previously published oscillating $\mathrm{pH}$ model (Cycle I) at $37^{\circ} \mathrm{C}$ for 5-7 days to mimic the daily changes in oral conditions. A modified $\mathrm{pH}$-cycling model (Cycle II) was applied to further evaluate the efficacy of CS-AMEL hydrogel for biomimetic repair of human enamel with caries-like lesions. In 
Cycle I, each 24-hours cycle involved 6 hours of demineralization and 18 hours of remineralization. During each period in Cycle II, blocks were immersed for 8 hours in modified remineralization solution, and then 16 hours in remineralization solution. The process of $\mathrm{pH}$ cycling is illustrated in Figure 1. CS-AMEL treatments were carried out 2 times daily, before and after demineralization (or modified remineralization) process. During each treatment, approximately $20 \mu \mathrm{CS}-\mathrm{AMEL}$ hydrogel was applied to the lesion surfaces, and then treated enamel blocks were left for 15 minutes in air at room temperature.

\subsection{Characterization}

SEM imaging was performed on a field emission scanning electron microscope (JEOL JSM-7001F). The tooth samples were sputtered with $\mathrm{Au}$ and observed under an accelerating voltage of $15 \mathrm{kV}$. X-ray diffraction (XRD) patterns were recorded on a Rigaku Diffractometer with $\mathrm{Cu} \mathrm{Kr}$ radiation $(\lambda=1.542 \AA)$ operating at $70 \mathrm{kV}$ and $50 \mathrm{~mA}$ with a step size of $0.02^{\circ}$, at a scanning rate of $0.1^{\circ} \mathrm{s}^{-1}$ in a $2 \theta$ range from $10^{\circ}$ to $60^{\circ}$. Cross-sections for fluorescence images were prepared by cutting the tooth blocks with a low-speed diamond saw. Fluorescence images were obtained using a Leica DMI3000B fluorescence microscope.

\section{Results}

The high mineral content of enamel, which makes this tissue the hardest in the human body, also makes it susceptible to a demineralization process that can result in dental erosion or caries. To evaluate the efficacy of CS-AMEL hydrogel at remineralizing these lesion types under $\mathrm{pH}$-cycling conditions, both artificial erosive lesions and incipient carious lesions were produced on human enamel.

\subsection{Treatment of erosive lesions}

After 30 seconds treatment with $30 \%$ phosphoric acid, the enamel surface became porous with discontinuous and broken crystals, resembling natural erosive lesions on enamel (see Figure 2A).

Figure 2. (A) SEM image of enamel etched with
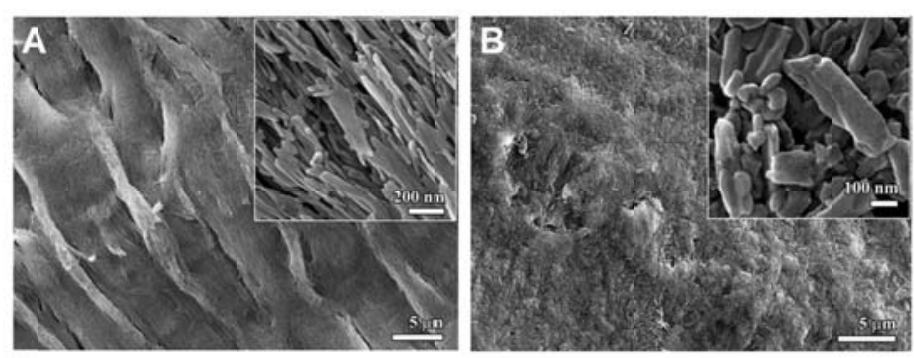
$30 \% \mathrm{H}_{3} \mathrm{PO}_{4}$ for 30 seconds. (B-C) SEM images of enamel blocks after 5 days of cycle I (B) without and (C) with CS-AMEL hydrogel treatment. Insets show the images at a higher magnification. (D) XRD spectra of etched enamel (black) and repaired enamel blocks after 5 days of cycle I (blue) with and (red) without CS-AMEL hydrogel treatment.
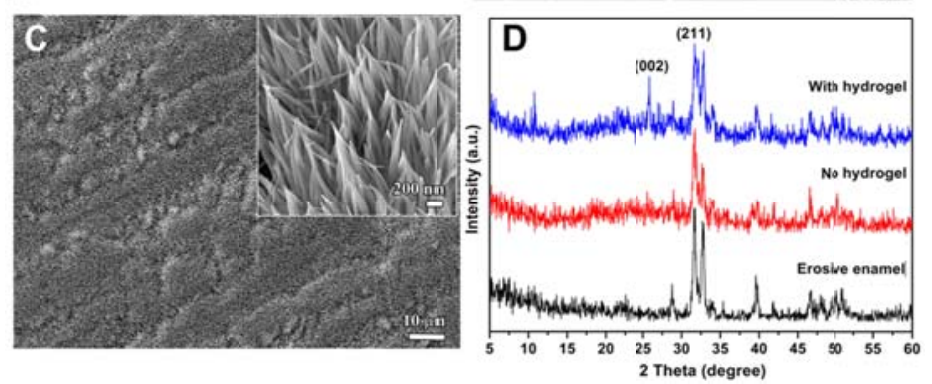

After 5 days of $\mathrm{pH}$ cycle I without CS-AMEL treatment, the etched enamel was remineralized to a limited extent because of the supersaturated calcium and phosphate ions in the remineralization solution. However, the organized structure of enamel was not regained, and only irregular crystals were observed on the enamel surface (see Figure 2B). In contrast to the control sample, a remarkably uniform synthetic layer composed of oriented apatite crystals formed on the surface of CS-AMEL-treated enamel after 5 days of pH cycle I (see Figure 2C). The orientation of the newly grown crystals was 
further confirmed by X-ray diffraction (XRD). Figure 2D shows the XRD spectra of etched enamel and repaired enamel after 5 days of cycle I with and without CS-AMEL hydrogel treatment. All of the diffraction peaks can be readily indexed to hexagonal phase hydroxyapatite (JCPDS 09-0432) crystals. In comparison with the sample without CS-AMEL treatment, the XRD spectrum of enamel repaired by CS-AMEL hydrogel showed an obvious 002 peak, indicating an improvement in the orientation of crystals (see Figure 2D). The SEM and XRD results clearly demonstrate the effectiveness of CS-AMEL hydrogel at forming a new organized layer of enamel-like crystals on the surface of erosive lesions in a pH-cycling system.

\subsection{Treatment of early carious lesions (artificial white spot lesions)}

To generate simulated incipient carious lesions in vitro, enamel blocks were subjected to a demineralization solution with a $\mathrm{pH}$ of 4.6. Figure 3 shows the fluorescent images and XRD spectra of sound enamel and the demineralized enamel. For sound enamel, continuous and strong fluorescence can be observed because of the high mineral content and the uniform molecular environment of the chromophore (see Figure 3A) ${ }^{[21,22]}$. Only a few weak reflections can be seen in the XRD pattern due to the presence of a smear layer resulted from the grinding process with the silicon-carbide paper (see Figure 3B). After immersing the enamel blocks in demineralization solution at $37^{\circ} \mathrm{C}$ for 7 days, a chalky white spot was clearly seen on the enamel surface, indicating an area of enamel demineralization (inset in Figure 3C). In the clinic, the appearance of a white spot is the earliest sign of a new carious lesion on a tooth. These white spot lesions lose their translucency because of the extensive subsurface porosity caused by demineralization and should be distinguished from developmental white spot hypocalcifications of enamel ${ }^{[23]}$. In addition, decreased fluorescence was observed in a cross-section of the demineralized enamel, showing the formation of a subsurface lesion with a depth of $\sim 100 \mu \mathrm{m}$ (see Figure 3C). The demineralization process also removed the smear layer on the enamel surface, resulting in a stronger XRD reflection compared to the healthy enamel (see Figure 3D). Both fluorescent images and XRD spectra demonstrated the successful formation of artificial early caries-like lesions in the enamel in our in vitro model.
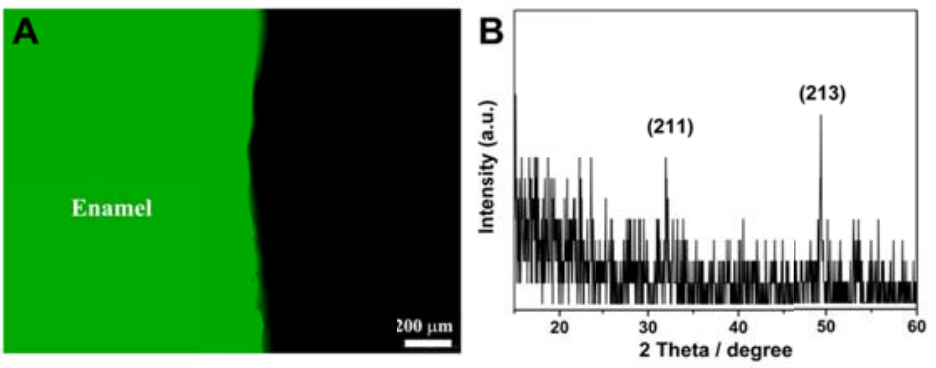

Figure 3. Representative fluorescent images of cross-sections of (A) healthy enamel and (C) demineralized enamel. Inset: photograph of a demineralized enamel block showing a white spot lesion on the tooth sample (red square). XRD spectra of (B) healthy enamel surface and (D) enamel surface with the caries-like lesions.
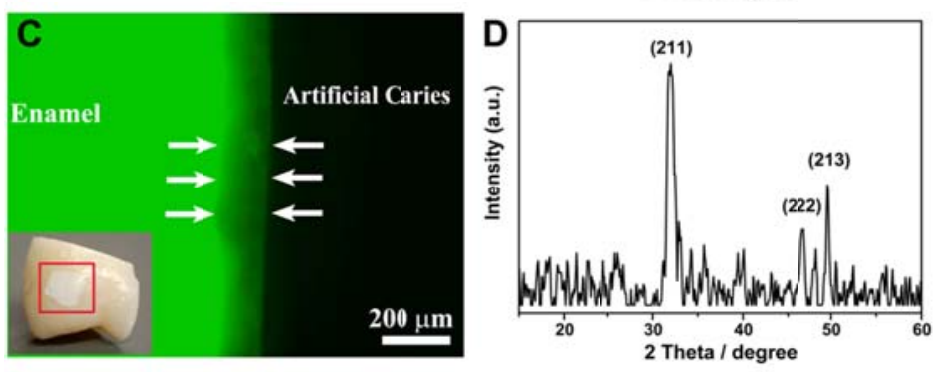

Early carious lesions are amenable to remineralization or arrest but if the demineralization process is not stopped, the intact enamel surface eventually collapses and cavitates ${ }^{[23]}$. While the conventional treatments have the effect of retarding the progression of tooth decay through the use of remineralizing agents, none of these methods can recover the lost enamel or form oriented enamel-like apatite crystals that are strongly attached to natural enamel. In our study, the depth of untreated caries-like lesions increased from $\sim 100 \mu \mathrm{m}$ to $\sim 150 \mu \mathrm{m}$ after 7 days of cycle I, as shown in Figure 4A. In contrast, the depth of the lesions significantly decreased from $\sim 100 \mu \mathrm{m}$ to $\sim 50 \mu \mathrm{m}$ after 7 days of cycle I with CS-AMEL hydrogel treatment (see Figure 4B). 

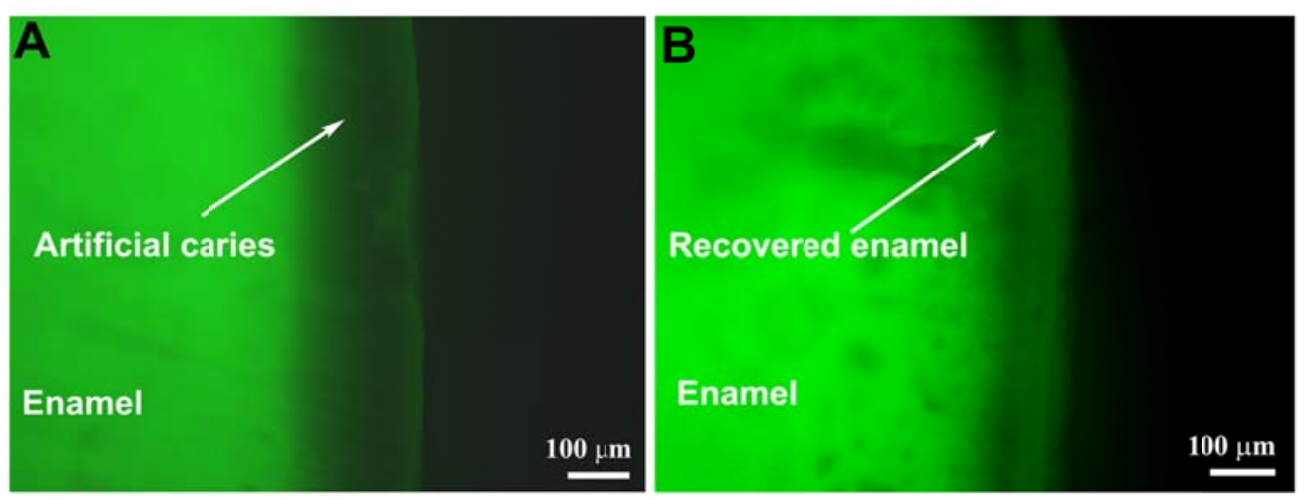

Figure 4. Representative fluorescent images of cross-sections of enamel blocks after 7 days of cycle I without (A) and with (B) CS-AMEL hydrogel treatment

Furthermore, the XRD spectra of the repaired enamel showed a high intensity ratio of (002) and (211) peaks (I $(002) / \mathrm{I}(211)=2.323)$, indicating that correct orientation of apatite crystals was achieved after treatment with CS-AMEL hydrogel (see Figure 5) ${ }^{[24]}$.

Figure 5. XRD spectrum of enamel surface after 7 days of cycle I with CS-AMEL hydrogel treatment
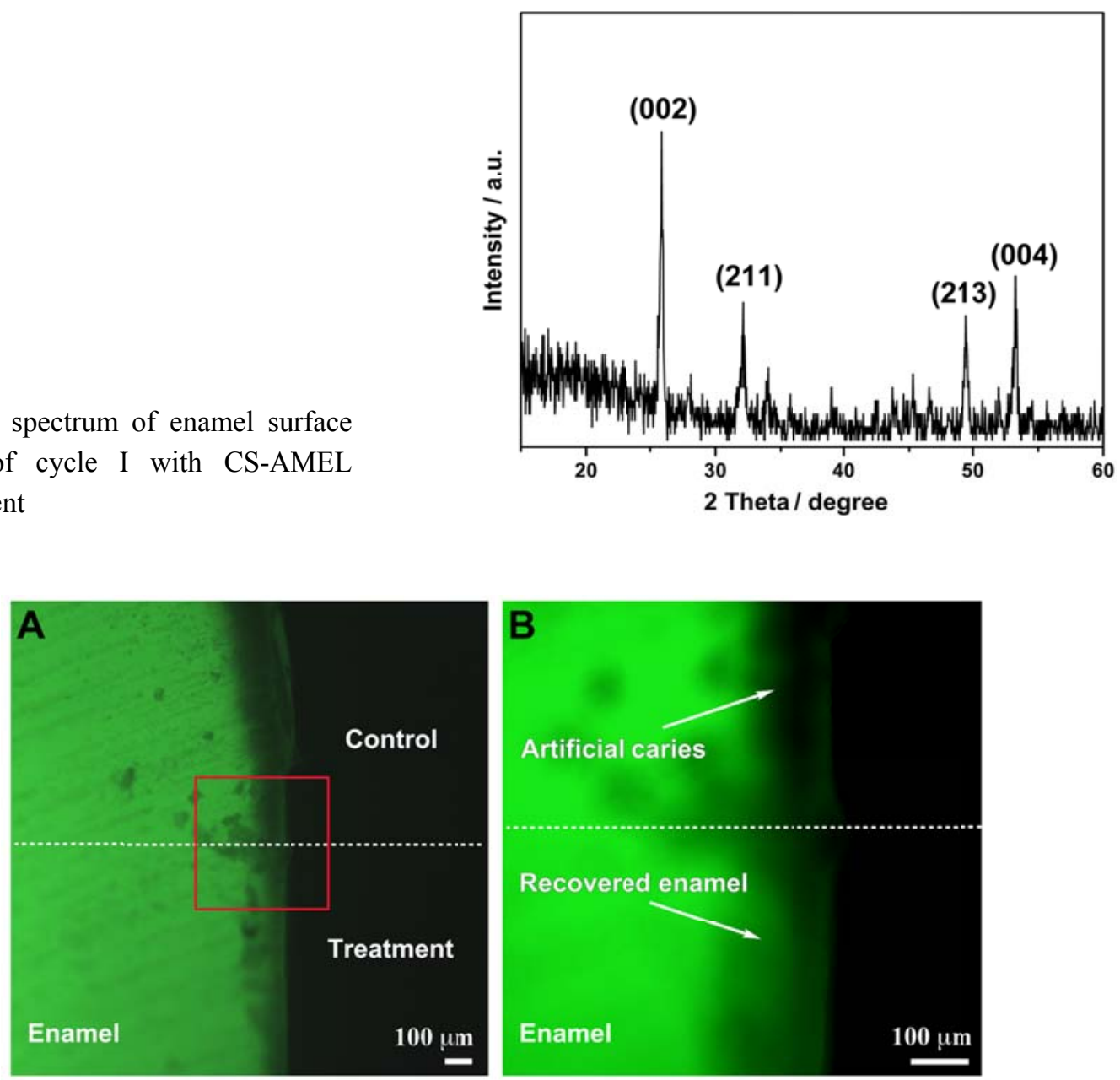

Figure 6. Representative fluorescent images of cross-sections of enamel blocks after 7 days of cycle II without (top) and with (bottom) CS-AMEL hydrogel treatment. Rectangle in (A) represents the selected area corresponding to (B). 
To further evaluate the efficacy of CS-AMEL hydrogel in the repair of enamel with caries-like lesions, a modified pH-cycling model (cycle II) was applied to mimic the oral environment during the nighttime. Based on the finding that the salivary $\mathrm{pH}$ during the nighttime is around 6.5 in the healthy oral cavity ${ }^{[25]}$, a modified remineralization solution with a $\mathrm{pH}$ of 6.5 was utilized in cycle II instead of the demineralization solution ( $\mathrm{pH} 4.6)$ in cycle I. In addition, the duration of treatment in the modified remineralization solution was set to 8 hours to simulate the typical duration of nighttime sleep. To obtain a better comparison, part of the white spot lesion was covered with nail varnish (white arrows in Figure 6A) before subjecting it to $\mathrm{pH}$ cycle II. Because of the protection of nail vanish, the progression of the carious lesion was stopped in the control. No obvious changes in lesion depth could be observed in the region covered by nail vanish after 7 days of cycle II. In contrast, the carious lesion decreased from $\sim 100 \mu \mathrm{m}$ to $\sim 30 \mu \mathrm{m}$ with the CS-AMEL hydrogel treatment after 7 days of cycle II. Interestingly, some parts of lesions were almost recovered by remineralized crystals. The fluorescent images and XRD analysis clearly revealed that CS-AMEL hydrogel is effective at repairing early carious lesions of the enamel by regrowing enamel-like crystals.

\section{Discussions}

In our previous in vitro studies, we have demonstrated the potential of CS-AMEL hydrogel in biomimetic reconstruction of dental enamel. Chitosan is a linear polysaccharide composed of randomly distributed $\beta$-(1-4)-linked D-glucosamine (deacetylated unit) and N-acetyl-D-glucosamine (acetylated unit). In the CS-AMEL hydrogel, the potential advantage of chitosan is to provide effective protection from enamel erosion and by interacting with amelogenin to avoid its loss into the saliva, at $\mathrm{pH}$ values below the $\mathrm{pKa}$ of chitosan (6.5) ${ }^{[9]}$. On the other hand, amelogenin assemblies carried in chitosan hydrogel could stabilize Ca-P clusters and guide arrangement of the clusters into linear chains that eventually evolve into enamel-like co-aligned crystals anchored to the natural enamel substrate ${ }^{[9]}$. This in situ regrowth promoted a dense interface and a strong bonding between the newly grown layer and the tooth surface. Our previous in vitro study has shown that the newly grown layer formed in the CS-AMEL hydrogel was tightly bound to the enamel surface and the organized structure was unaffected even after an ultrasonic washing process ${ }^{[9]}$. In addition, the hardness and elastic modulus of etched enamel were increased significantly after treatment with CS-AMEL hydrogel. Furthermore, CS-AMEL hydrogel is easy to handle under clinical conditions. We have designed a user-friendly dental tray that will be custom-made for the patients and can be easily used for the application of CS-AMEL hydrogel. However, further testing is still necessary to establish whether it is effective in the real oral cavity, which has a more complex environment for crystal growth. The present experiments under $\mathrm{pH}$-cycling conditions described here constitute one step towards that goal.

One major difference between typical in vitro studies and the natural oral cavity is the fluctuating $\mathrm{pH}$ of the saliva, especially the acidic environment after consuming food. We sought to determine here whether those conditions affect the efficacy of CS-AMEL hydrogel during treatment for erosive or carious lesions. To tackle this challenge, tooth samples modeling erosive and early carious lesions were subjected to a pH-cycling model involving an acidic challenge (pH 4.6) of demineralization solution in the present study. After 5 days of $\mathrm{pH}$ cycling with CS-AMEL treatment, an organized layer of enamel-like crystals was regrown on the surface of erosive lesions, indicating that both chitosan and amelogenin were still stable under the acidic challenge, even though chitosan is considered to be soluble at $\mathrm{pH}<6.5^{[26,27]}$. However, in this case it is still able to re-grow the erosive enamel during the $\mathrm{pH}$ cycling due to its unique adhesive property. In the demineralization solution, the amino groups of chitosan capture hydrogen ions, resulting in an overall positive charge that gives a bioadhesive property to negatively charged surfaces of erosive enamel. It has been reported that this positively charged chitosan layer might act as a barrier against acid penetration, inhibiting the demineralization process ${ }^{[28,29]}$. Moreover, the $\mathrm{pH}$-sensitivity of chitosan may provide protection for amelogenin under acidic conditions ${ }^{[9]}$. At $\mathrm{pH}$ values below the pKa of chitosan (6.5), it can interact with amelogenin through electrostatic interaction to avoid protein loss into the saliva. When the normal $\mathrm{pH}$ of the saliva is restored (to the range 6.3-7.0), the weakly interacting amelogenin is released from the chitosan to regulate the remineralization of enamel. Together with this evidence from previous studies, our present results clearly validate the effectiveness of CS-AMEL hydrogel at repairing erosive enamel lesions in a pH-cycling system. 
Another concern is whether the CS-AMEL hydrogel can repair early carious lesion. Unlike superficial erosive lesions, in early caries the enamel has an intact mineral layer on top of the lesion. We therefore sought to test whether CS-AMEL hydrogel could penetrate through this mineral layer to reach the subsurface lesion. Both in vivo and ex vivo studies have observed that the surface morphology of an initial carious lesion is different from that of sound enamel ${ }^{[30,31]}$. In initial carious lesions, the relatively intact surface layer generally exhibits a clearer perikymata pattern and in numerous studies so-called focal holes have been seen ${ }^{[32]}$. Using scanning electromicroscopy, de Marsillac et al. found that micro-sized diffusion pathways through intercrystalline and interprismatic spaces could be detected on the surface of carious enamel ${ }^{[33]}$. On the other hand, our previous investigation has revealed that CS-AMEL hydrogel works through the nano-sized amelogenin-Ca-P clusters that eventually evolve into enamel-like co-aligned crystals ${ }^{[9]}$. Based on previous observations, it is reasonable to believe that this pseudo-intact surface layer is permeable by the active ingredient in CS-AMEL hydrogel. Indeed, in the present study, the artificial carious lesions were successfully repaired by the CS-AMEL hydrogel in the pH-cycling systems. In cycle I, the depth of the artificial incipient carious lesions was reduced by up to $50 \%$. After 7 days of cycle II with the CS-AMEL treatment, the depth of the artificial caries was significantly reduced by up to $\sim 70 \%$. Some portions of the carious lesions were almost refilled by remineralized crystals in the CS-AMEL-treated samples. In comparison, in a previous study it was reported that only $\sim 24 \%$ of caries was recovered after 12 days of $\mathrm{pH}$ cycling with $\mathrm{NaF}$ treatment ${ }^{[34]}$. The CS-AMEL-treated sample in this study exhibited a superior degree of recovery in terms of depth compared to other treatments reported in the literature.

In addition, the results from this study may provide guidance for the design of future clinical study protocols for testing CS-AMEL. Considering the successful repair of carious lesions in cycle II, patients could be instructed to apply the hydrogel before and after sleep. Nevertheless, it should be noted that this study did not take into account the effect of the saliva proteins, which is very important for the clinical application of CS-AMEL hydrogel. Among the non-immunologic salivary protein components, there are enzymes (lysozyme, lactoferrin, and peroxidase), mucin glycoproteins, agglutinins, histatins, proline-rich proteins, statherins, and cystatins ${ }^{[35]}$. Lysozyme can degrade the chitosan molecule ${ }^{[36]}$, and it may also perturb and interfere with the native intermolecular amelogenin interactions because of its positive charge at neutral $\mathrm{pH}^{[37]}$. It has also been reported that proline-rich proteins and statherins inhibit the spontaneous precipitation of calcium phosphate salts and the growth of hydroxyapatite crystals on the tooth surface ${ }^{[35]}$. Examining the effect of saliva on the hydrogel is a subject for future investigation.

In conclusion, the efficacy of amelogenin-chitosan (CS-AMEL) hydrogel for the biomimetic repair of human enamel with erosive or carious lesions was investigated in two $\mathrm{pH}$-cycling systems. The results showed that CS-AMEL hydrogel is effective at $\mathrm{pH} 4.6$, which is similar to the $\mathrm{pH}$ of the mouth after consumption of food, as well as at $\mathrm{pH} 6.5$, which is the average $\mathrm{pH}$ during the nighttime. CS-AMEL hydrogel was effective in forming a new organized layer of enamel-like crystals on the surface of erosive lesions. In addition, CS-AMEL could repair artificial incipient caries by regrowing oriented crystals and reducing the depth of the lesions by up to $50 \%-70 \%$ under $\mathrm{pH}$-cycling conditions. This study clearly demonstrates the potential of CS-AMEL hydrogel for the prevention, restoration, and treatment of defective dental enamel. Furthermore, the results presented here may promote the appropriate design for clinical trials; however, the effect of salivary proteins should also been considered in human studies.

\section{Acknowledgements}

This work was supported by NIH-NIDCR grants DE-13414 and DE-020099 to J.M.O and the USC Coulter Translational Partnership Program. The authors would like to thank the Center for Electron Microscopy and Microanalysis (CEMMA) at USC for electron microscopy.

\section{References}

[1] Eccles JD. Dental erosion of nonindustrial origin. A clinical survey and classification. J Prosthet Dent. 1979; 42: 649-53. http://dx.doi.org/10.1016/0022-3913(79)90196-3 
[2] Lussi A, Jaggi T, Scharer S. The influence of different factors on in vitro enamel erosion. Caries Res. 1993; 27: $387-93$. PMid:8242676. http://dx.doi.org/10.1159/000261569

[3] Jain P, Shankar A, Ramaiah S. Dental caries and social deprivation. Lancet. 2007; 369: 639. http://dx.doi.org/10.1016/S0140-6736(07)60304-3

[4] Selwitz RH, Ismail AI, Pitts NB. Dental caries. Lancet. 2007; 369: 51-9. http://dx.doi.org/10.1016/S0140-6736(07)60031-2

[5] Hannig M, Hannig C. Nanomaterials in preventive dentistry. Nat Nanotechnol. 2010; 5: 565-9. PMid:20581832. http://dx.doi.org/10.1038/nnano.2010.83

[6] Yengopal V, Mickenautsch S. Caries preventive effect of casein phosphopeptide-amorphous calcium phosphate (CPP-ACP): a meta-analysis. Acta Odontol Scand. 2009; 67: 321-32. PMid:19701818. http://dx.doi.org/10.1080/00016350903160563

[7] Li JL, Xie XQ, Wang Y, et al. Long-term remineralizing effect of casein phosphopeptide-amorphous calcium phosphate (CPP-ACP) on early caries lesions in vivo: A systematic review. J Dent. 2014; 42: 769-77. PMid:24705069. http://dx.doi.org/10.1016/j.jdent.2014.03.015

[8] Ruan QC, Moradian-Oldak J. Amelogenin and enamel biomimetics. J Mater Chem B. 2015; 3: 3112-29. PMid:26251723. http://dx.doi.org/10.1039/C5TB00163C

[9] Ruan QC, Zhang YZ, Yang XD, et al. An amelogenin-chitosan matrix promotes assembly of an enamel-like layer with a dense interface. Acta Biomater. 2013; 9: 7289-97. PMid:23571002. http://dx.doi.org/10.1016/j.actbio.2013.04.004

[10] Ruan QC, Moradian-Oldak J. Development of Amelogenin-chitosan Hydrogel for In vitro Enamel Regrowth with a Dense Interface. J Vis Exp. 2014; 89: e51606. http://dx.doi.org/10.3791/51606

[11] Ruan QC, Siddiqah N, Li XC, et al. Amelogenin-chitosan matrix for human enamel regrowth: effects of viscosity and supersaturation degree. Connect Tissue Res. 2014; 55: 150-4. PMid:25158201. http://dx.doi.org/10.3109/03008207.2014.923856

[12] Moradian-Oldak J. Protein-mediated enamel mineralization. Front Biosci-Landmrk. 2012; 17: 1996-2023. http://dx.doi.org/10.2741/4034

[13] Humphrey SP, Williamson RT. A review of saliva: Normal composition, flow, and function. J Prosthet Dent. 2001 ; 85: 162-9. PMid:11208206. http://dx.doi.org/10.1067/mpr.2001.113778

[14] Meurman JH, Rytomaa I, Kari K, et al. Salivary Ph and Glucose after Consuming Various Beverages, Including Sugar-Containing Drinks. Caries Res. 1987; 21: 353-9. PMid:3475181. http://dx.doi.org/10.1159/000261039

[15] Cummins. Working Group Report 3: Role of models in assessing new agents for caries prevention. Adv Dent Res. $1995 ; 9: 338-9$. PMid:8615954. http://dx.doi.org/10.1177/08959374950090032201

[16] Buzalaf MA, Hannas AR, Magalhaes AC, et al. pH-cycling models for in vitro evaluation of the efficacy of fluoridated dentifrices for caries control: strengths and limitations. J Appl Oral Sci. 2010; 18: 316-34. PMid:20835565.

[17] ten Cate JM, Duijsters PP. Alternating demineralization and remineralization of artificial enamel lesions. Caries Res. 1982; 16: 201-10. PMid:6953998. http://dx.doi.org/10.1159/000260599

[18] ten Cate JM. Models and role models. Caries Res. 2015; 49 (Suppl 1): 3-10. PMid:25871413. http://dx.doi.org/10.1159/000380870

[19] White DJ. The application of in vitro models to research on demineralization and remineralization of the teeth. J Appl Oral Sci. 1995; 9: 175-93; discussion 94-7.

[20] Zero DT. In situ caries models. J Appl Oral Sci. 1995; 9: 214-30; discussion 31-4.

[21] Foreman PC. Fluorescent microstructure of mineralized dental tissues. Int Endod J. 1988; 21: 251-6. PMid:3251849. http://dx.doi.org/10.1111/j.1365-2591.1988.tb01007.x

[22] Angmar-Mansson B, ten Bosch JJ. Quantitative light-induced fluorescence (QLF): a method for assessment of incipient caries lesions. Dento maxillo facial radiology. 2001; 30: 298-307. PMid:11641727. http://dx.doi.org/10.1038/sj.dmfr.4600644

[23] Gugnani N, Pandit IK, Gupta M, et al. Caries infiltration of noncavitated white spot lesions: A novel approach for immediate esthetic improvement. Contemp Clin Dent. 2012; 3: S199-202. PMid:23230363. http://dx.doi.org/10.4103/0976-237X.101092

[24] Li L, Mao CY, Wang JM, et al. Bio-Inspired Enamel Repair via Glu-Directed Assembly of Apatite Nanoparticles: an Approach to Biomaterials with Optimal Characteristics. Adv Mater. 2011; 23: 4695-11. PMid:21915920. http://dx.doi.org/10.1002/adma.201102773

[25] Watanabe M, Sano H, Tomita K, et al. A nocturnal decline of salivary $\mathrm{pH}$ associated with airway hyperresponsiveness in asthma. J Med Invest. 2010; 57: 260-9. PMid:20847526. http://dx.doi.org/10.2152/jmi.57.260

[26] Kumar MNVR. A review of chitin and chitosan applications. React Funct Polym. 2000; 46: 1-27. http://dx.doi.org/10.1016/S1381-5148(00)00038-9

[27] Liu WG, Sun SJ, Cao ZQ, et al. An investigation on the physicochemical properties of chitosan/DNA polyelectrolyte complexes. Biomaterials. 2005; 26: 2705-11. PMid:15585274. http://dx.doi.org/10.1016/j.biomaterials.2004.07.038 
[28] Arnaud TMS, Neto BD, Diniz FB. Chitosan effect on dental enamel de-remineralization: An in vitro evaluation. J Dent. 2010; 38: 848-52. PMid:20600551. http://dx.doi.org/10.1016/j.jdent.2010.06.004

[29] Lee HS, Tsai S, Kuo CC, et al. Chitosan adsorption on hydroxyapatite and its role in preventing acid erosion. J Colloid Interf Sci. 2012; 385: 235-43. PMid:22840874. http://dx.doi.org/10.1016/j.jcis.2012.06.074

[30] Pinto CF, Paes Leme AF, Cavalli V, et al. Effect of 10\% carbamide peroxide bleaching on sound and artificial enamel carious lesions. Braz Dent J. 2009; 20: 48-53. PMid:19466231. http://dx.doi.org/10.1590/S0103-64402009000100008

[31] Vashisht R, Kumar A, Indira R, et al. Remineralization of early enamel lesions using casein phosphopeptide amorphous calcium Phosphate: an ex-vivo study. Contemp Clin Dent. 2010; 1: 210-3. PMid:22114422.

[32] Arends J, Christoffersen J. The nature of early caries lesions in enamel. J Dent Res. 1986; 65: 2-11. PMid:3510230

[33] de Marsillac Mde W, Vieira Rde S. Assesment of artificial caries lesions through scanning electron microscopy and cross-sectional microhardness test. Indian J Dent Res. 2013; 24: 249-54. PMid:23965457. http://dx.doi.org/10.4103/0970-9290.116699

[34] Yang Y, Lv XP, Shi W, et al. 8DSS-promoted remineralization of initial enamel caries in vitro. J Dent Res. 2014 ; 93 : 520-4. PMid:24496294. http://dx.doi.org/10.1177/0022034514522815

[35] de Almeida Pdel V, Gregio AM, Machado MA, et al. Saliva composition and functions: a comprehensive review. J Contemp Dent Pract. 2008; 9: 72-80. PMid:18335122.

[36] Tomihata K, Ikada Y. In vitro and in vivo degradation of films of chitin and its deacetylated derivatives. Biomaterials. 1997; 18: 567-75. http://dx.doi.org/10.1016/S0142-9612(96)00167-6

[37] Bonde JS, Bulow L. Use of human amelogenin in molecular encapsulation for the design of $\mathrm{pH}$ responsive microparticles. Bmc Biotechnol. 2012; 12. http://dx.doi.org/10.1186/1472-6750-12-25 